\title{
ECONOMIA CRIATIVA E LIDERANÇA CRIATIVA: UMA ASSOCIAÇÃO (IM) POSSÍVEL?
}

\author{
Felipe Carvalhal \\ carvalhalfelipe@gmail.com \\ Henrique Muzzio \\ henrique.muzzio@ufpe.br
}

Universidade Federal de Pernambuco - Recife, PE / Brasil

http://dx.doi.org/10.1590/1413-2311.0032015.54929

Recebido em 10/02/2015

Aprovado em 21/12/2015

Disponibilizado em 31/12/2015

Avaliado pelo sistema "double blind review"

Revista Eletrônica de Administração

Editor: Luís Felipe Nascimento

ISSN 1413-2311 (versão "on line")

Editada pela Escola de Administração da Universidade Federal do Rio Grande do Sul.

Periodicidade: Quadrimestral

Sistema requerido: Adobe Acrobat Reader

\section{RESUMO}

Atuando em uma economia caracterizada por indivíduos criativos, fontes de vantagem competitiva e crescimento nas economias pós-industriais, os líderes das organizações assumem enorme importância no ambiente competitivo atual, tornando-se um diferencial, visto que o estilo de liderar reflete sobre o desempenho da organização. Diante disso, este artigo procurou analisar a liderança exercida por gestores da economia criativa, com vistas à liderança criativa. Especificamente buscou-se conhecer a atuação deles diante dos fatores da liderança criativa e os aspectos da criatividade, além de verificar a relação da criatividade e produtividade com essa liderança. Para tal, foi realizada uma pesquisa de natureza qualitativa de caráter exploratório por meio de estudo de casos múltiplos. Foram realizadas entrevistas semiestruturadas com três gestores da economia criativa na cidade do Recife-PE, Brasil. Foi constatado que os gestores da economia criativa ainda não exercem uma liderança criativa em sua plenitude, mas parece haver um esforço nessa direção, com relevância nos fatores clima, ideias próprias, resiliência e a ativação em rede; enquanto que deve melhorar o comportamento que tangem à plataforma de entendimento, visão compartilhada, e aprendizado vindo da experiência. Observou-se que há uma relação de simultaneidade entre a liderança criativa e uma melhor produtividade, apoio e incentivo à criatividade no ambiente de trabalho, onde o aspecto primordial para as pessoas aflorarem sua criatividade é se sentirem bem no local de trabalho.

REAd | Porto Alegre - Edição 82 - N 3 - setembro/dezembro 2015 - p. 659-688 
ECONOMIA CRIATIVA E LIDERANÇA CRIATIVA: UMA ASSOCIAÇÃO (IM)

POSSÍVEL?

Palavras-chave: Liderança; Liderança Criativa; Economia Criativa; Indústrias Criativas; Criatividade.

\title{
CREATIVE ECONOMYANDCREATIVE LEADERSHIP: AN (IM) POSSIBLE ASSOCIATION?
}

\begin{abstract}
Operating in an economy characterized by creative individuals, sources of competitive advantage and grow thin post-industrial economies, the leaders of organizations assume enormous importance in today's competitive environment, becoming a differentiator, since the style of leadership reflects on the performance of organization. Seen it, this article aims to analyze the leadership exercised by managers of creative economy, with a view to creative leadership. Sought to understand the performance of them on creative leadership factors and aspects of creativity, and to verify the relationship of creativity and productivity with this leadership. We did a qualitative research nature of exploratory character of multiple case studies. Semi-structured interviews were conducted with three managers of the creative economy in the city of Recife, Brazil. It was realized that the managers of creative economy hasn't engaged in a creative leadership in its fullness, but there seems to be an effort in that direction, with relevance to climate factors, own ideas, resilience and network activation; While that should improve the behavior in relation to common ground, shared vision, and learning from the experience. It was observed that there is a relationship between concurrency creative leadership and a better productivity and support and encouragement for creativity in the workplace, where the primary feature for people to come forth your creativity is to feel good at work.
\end{abstract}

Keywords: Leadership; Creative Leadership; Creative Economy; Creative Industries; Creativity

ECONOMÍACREATIVAY LIDERAZGOCREATIVA: ¿UNA ASOCIACIÓN (IM)

\section{POSIBLE?}

\section{RESUMEN}

Al operar en una economía caracterizada por individuos creativos, fuentes de ventaja competitiva y el crecimiento en las economías post-industriales, los dirigentes de las organizaciones asumen enorme importancia en el entorno competitivo actual, convirtiéndose en un elemento diferenciador, ya que el estilo de liderazgo se refleja en el rendimiento de organización. Lo he visto, este artículo tiene como objetivo analizar el liderazgo delos gestores de la economía creativa, con vistas aun liderazgo creativa. Específicamente dirigido a investigar el papel de estos factores en los aspectos creativos de liderazgo y la creatividad; y la relación de la creatividad y la productividad con este liderazgo. Con este fin, se realizó un estudio de naturaleza cualitativa de carácter exploratorios de múltiples estudios de caso. Fueron realizadas entrevistas semi-estructuradas con tres directivos de la economía creativa en la ciudad de Recife-PE, Brasil. Se observó que los gestores de la economía creativa no

REAd | Porto Alegre - Edição 82 - Nº 3 - setembro/dezembro 2015 - p. 659-688 


\section{Felipe Carvalhal \& Henrique Muzzio}

ejercen una liderazgo creativa en su plenitud, pero parece que hay un esfuerzo en esa dirección, con relevancia a los factores climáticos, propias ideas, capacidad de recuperación y la activación de la red; mientras que debería mejorar el comportamiento que se refieren a la comprensión, la plataforma de visión compartida, y el aprendizaje de la experiencia. Se observó que existe una relación de simultaneidad entre el liderazgo creativo y mejor productividad y el apoyo a la creatividad y alentador en el lugar de trabajo, donde la característica principal para que las personas salen de su creatividades sentirse bien en el trabajo.

Palabras clave: Liderazgo; Liderazgo Creativa; Economía Creativa; Industrias Creativas; Creatividad.

\section{INTRODUÇÃO}

Nas últimas décadas a criatividade tem ganhado uma atenção especial, tanto que as empresas não só passaram a reconhecer sua importância como insumo de produção, mas também perceberam seu papel transformador no sistema produtivo. Para Florida (2011), as áreas estratégicas das empresas voltaram os olhos para o uso da criatividade como recurso essencial para geração de valor, configurando uma nova economia, a economia criativa. Segundo Miguez (2007), esta se refere ao conjunto distinto de atividades assentadas na criatividade, cujos produtos ou serviços incorporam propriedade intelectual, e englobam desde atividades tradicionais como o artesanato, às complexas cadeias produtivas dos games e softwares, por exemplo. Segundo ele, é possível encontrar múltiplas imbricações e importantes implicações fazendo com que a questão ultrapasse o campo de atuação inicial, a cultura, e invada outras áreas do conhecimento, especialmente a economia e a gestão. Já Pratt e Hutton (2013) destacam as potencialidades e evidentes impactos do ponto de vista do desenvolvimento, tendo feito com que a comunidade internacional detenha sua atenção sobre a problemática, em particular, quanto às possibilidades que esta economia encara para os países menos desenvolvidos, sendo apontado por autores, a exemplo Miguez (2007) e Deheinzelin (2006), como uma das principais estratégias de desenvolvimento para o século XXI (MIGUEZ, 2007).

A economia criativa abrange um vasto conjunto de atividades, sendo um dos setores mais dinâmicos da economia global. Sobre isso, a Conferência das Nações Unidas sobre Comércio e Desenvolvimento (UNCTAD, 2010) destacou que apesar da crise econômica, em 2008, as exportações mundiais de bens e serviços criativos alcançaram \$ 592 bilhões em 2008, mais do que o dobro do número de 2002; representando uma taxa de crescimento anual REAd | Porto Alegre - Edição 82 - N 3 - setembro/dezembro 2015 - p. 659-688 


\section{ECONOMIA CRIATIVA E LIDERANÇA CRIATIVA: UMA ASSOCIAÇÃO (IM) POSSÍVEL?}

de $14 \%$ para a economia criativa neste período, superior à de outros setores. No Brasil, dados mostram alinhamento a essa tendência internacional. Segundo o relatório da Firjan (2012), em 2011, 243 mil empresas formavam o núcleo da indústria criativa, gerando Produto Interno Bruto equivalente a R\$ 110 bilhões, ou 2,7\% de tudo o que é produzido no Brasil. Em relação à região Nordeste, destacam-se os estados do Ceará, Pernambuco e Bahia, como os de maiores representatividades no núcleo criativo.

De acordo com Muzzio e Paiva Júnior (2014), essa economia é caracterizada pela composição no mercado de trabalho de indivíduos criativos, sendo uma fonte de vantagem competitiva e um mecanismo importante para o crescimento nas economias pós-industriais. Visto isso, e percebido o destaque dessa nova economia, faz-se necessário conhecer e destacar a atuação dos líderes, que, segundo Carvalhal (2012), são indivíduos responsáveis pela definição, implementação e disseminação de estratégias, além do envolvimento dos funcionários para o alcance dos objetivos da organização, e assumem enorme importância no ambiente competitivo atual, tornando-se um diferencial, visto que o estilo de liderar reflete sobre o desempenho dos liderados, impactando no desempenho da organização.

É válido ressaltar, que apesar de sua ampla presença na literatura, principalmente sobre gestão, a liderança é um fenômeno multifacetado e com diversos entendimentos, o que ressalta a importância de uma compreensão mais crítica de suas teorias e abordagens, especialmente no contexto atual, onde diversos fatores ambientais e organizacionais demandam novas práticas de gestão, sendo também destacada a relevância de novos perfis de liderança. Para efeito deste estudo, será dado enfoque à liderança criativa, a qual sugere que líderes e liderados podem conseguir elevados níveis de criatividade, inovação em equipes de trabalho e atingir ou superar as expectativas de desempenho estabelecidas pela organização, a partir do surgimento de estruturas benignas no grupo, sendo estas favorecidas por um estilo de liderança participativo e apoiador, que enfatize a mutualidade e a cooperação (RICKARDS e MOGER, 2000).

Diante do exposto, este trabalho possui como objetivo geral, analisar a liderança exercida por gestores da economia criativa, com vistas à liderança criativa. Especificamente, pretende-se conhecer a atuação deles diante dos fatores da liderança criativa e os aspectos da criatividade; e verificar a relação da criatividade e produtividade a essa liderança. Para o alcance desse objetivo, esse artigo conta com algumas seções. A primeira versa sobre

REAd | Porto Alegre - Edição 82 - N 3 - setembro/dezembro 2015 - p. 659-688 


\section{Felipe Carvalhal \& Henrique Muzzio}

economia criativa e sua compreensão geral. Em seguida, focamos na perspectiva da liderança e, mais especificamente, na liderança criativa. Depois dos procedimentos metodológicos seguidos, é exposta a pesquisa de campo e seus desdobramentos a partir de três casos estudados. E, por fim, são apresentadas as considerações finais.

\section{ECONOMIA CRIATIVA}

Ao realizar uma análise histórica sobre o surgimento da economia criativa, Miguez (2007) desperta para a possibilidade de podermos compreender este fenômeno enquanto uma ampliação contemporânea da economia da cultura, e esta, como uma extensão dos limites que rondavam a economia das artes. Machado (2009) sustenta essa perspectiva, e ressalta que a conciliação entre essas áreas, ainda que tensa, existe, e requer alguns cuidados, visto que as atividades, bens e serviços culturais possuem dupla natureza, tanto econômica, quanto cultural, uma vez que são portadores de identidades, valores e significados, não devendo, portanto, ser tratadas como se tivessem valor apenas meramente comercial.

Apesar desse resgate, alguns teóricos (COSTA, SANTOS, 2011; PRATT; HUTTON, 2013; MACHADO, 2009; MIGUEZ, 2007) afirmam que a expressão economia criativa CreativeEconomy - é recente, com imbricado debate conceitual entre ela, e a expressão indústria criativa - Creative Industries. Para Miguez (2007), ainda que ambos os termos possam ser alcançados pelo expressivo debate, querendo significar um setor da economia, ou almejando tornar-se um campo específico do conhecimento, não deixam de constituir-se em uma novidade bastante recente. Esses dois termos configuram um campo de estudo em fase de solidificação, que desperta interesse crescente, configurando um debate que começa a ganhar relevo, mas ainda com lacunas de compreensão, um campo de conhecimento préparadigmático, em rota ascendente e ritmo crescente de constituição (COSTA; SANTOS, 2011; MIGUEZ, 2007; PRATT; HUTTON, 2013). Cohen et al. (2008) destacam a longa trajetória sobre essas duas linhas de abordagens, com tendência a fusão e complementariedade. Pratt e Hutton (2013) corroboram a afirmação argumentando que uma série de artigos e livros têm abordado o rápido aparecimento e aumento da estabilização de conceitos e o desenvolvimento de medidas no campo da economia criativa. Para pesquisadores como Miguez (2007), Pratt e Hutton (2013), Machado (2009) questões que remetem a ambos os termos, economia e indústria criativa encontram suas primeiras 


\section{ECONOMIA CRIATIVA E LIDERANÇA CRIATIVA: UMA ASSOCIAÇÃO (IM) POSSÍVEL?}

sistematizações em meados da década de 1990, reunidas sob o rótulo de indústrias criativas, sendo formuladas nos gabinetes governamentais.

Miguez (2007) ressalta que a identificação das indústrias criativas como um setor particular da economia vem do manifesto pré-eleitoral de 1997, do novo partido trabalhista inglês, o New Labour. Foi o Departamento de Cultura, Mídia e Esportes (DCMS) do Reino Unido que cunhou esse novo conceito, ao lançar o primeiro mapeamento das indústrias criativas, tendo como um dos objetivos mostrar que estas vão além do papel fundamental da cultura, e que possuem um vasto potencial de geração de empregos e riqueza, sendo, até agora, a definição mais comumente utilizada pelos países que já adotam as expressões economia e/ou indústrias. O termo foi formulado pela Creative Industries Task Force, grupo criado em 1997 pelo DCMS e diz que:

As indústrias criativas são aquelas que possuem sua origem na criatividade, habilidade e talento individuais e que têm potencial para geração de empregos e riquezas por meio da geração e exploração da propriedade intelectual. Isto inclui propaganda, arquitetura, o mercado de artes e antiguidades, artesanatos, design, design de moda, filme e vídeo, software de lazer interativo, música, artes cênicas, publicações, software e jogos de computador, televisão e rádio. (BRITISH COUNCIL, 2005, p. 5)

Um dos pontos mais importantes foi o lançamento do livro de Richard Caves, em 2000, Creative industries: contracts between art and commerce. Ele versou sobre as indústrias criativas, procurando identificar e discutir os variados problemas envolvendo a relação entre os diversos campos do fazer artístico, as atividades criativas, e a economia (CAVES, 2000). Para Miguez (2007), a expressão economia criativa em si, ao que tudo indica, aparece pela primeira vez em 2001, na matéria de capa da Business Week, intitulada The Creative Economy - the 21century corporation, e, posteriormente no título do livro de John Howkins, publicado em Londres, The creative economy - how people make Money from ideas. Howkins (2001) trouxe ao método britânico uma visão empresarial baseada nos conceitos mercadológicos de propriedade intelectual, onde expôs que marcas, patentes e direitos autorais forneciam os princípios para a transformação da criatividade em produto, lançando assim, a ideia de que as pessoas podem transformar criatividade em dinheiro. Já em 2005, ele alerta sobre as discussões importantes para a temática da economia e indústrias criativas (HOWKINS, 2005), onde aponta a necessidade de revisão do conceito; e a importância de promover a aproximação entre criatividade e inovação, permitindo assim, a inclusão da ciência no âmbito das indústrias criativas; e a elaboração de políticas públicas

REAd | Porto Alegre - Edição 82 - N 3 - setembro/dezembro 2015 - p. 659-688 


\section{Felipe Carvalhal \& Henrique Muzzio}

capazes de integrar as múltiplas dimensões e responder às várias demandas da economia criativa.

Outro autor que trouxe visibilidade ao tema foi o Richard Florida, com o livro The Rise of the Creative Class, em 2001, cujo foco teve os profissionais que trabalhavam com processos criativos, denominados de classe criativa. A esta pertence cientistas, artistas, poetas, arquitetos, formadores de opinião etc. $\mathrm{O}$ autor mostra dados e as características sociais dessa nova classe de trabalhadores e aborda o potencial de contribuição dela para o desenvolvimento. Para ele, as nações avançadas estão se movendo na direção de uma economia baseada na informação e no conhecimento, especificamente, na criatividade.

De acordo com Costa e Santos (2011), o aprofundamento do interesse acadêmico pelo tema é verificado na universidade australiana Queensl and University of Technology (QUT), em 2002. Miguez (2007) fala que o New Economy, Creativity and Consumption Symposium, evento realizado nessa universidade, propiciou o encontro de estudiosos e pesquisadores vinculados à recém-criada Creative Industries Faculty da QUT, à London School of Economics, ao Massachusetts Institute of Technology e à New York University com o objetivo central de avançar, conjuntamente, na reflexão sobre o significado e os impactos sociais e culturais da economia criativa e contribuir para a construção de uma agenda dedicada a esta temática. Podemos considerar que foi, a partir deste encontro, que o mundo despertou o interesse para esse novo olhar da criatividade, visto que ela em si não é uma novidade.

Na visão de Miguez (2007), no caso de países como o Brasil, África do Sul, Índia, Cingapura, China, dentre outros, o tema emerge com força a partir de 2004, com a realização, durante a XI Conferência da UNCTAD, em São Paulo, de um Painel dedicado exclusivamente à questão das indústrias criativas na perspectiva dos países em desenvolvimento, tornando essa Conferência um marco deste processo, exatamente pelo fato de ter recomendado a criação de uma instituição internacional dedicada à economia criativa, na perspectiva do fortalecimento e desenvolvimento deste setor, em países desse tipo.

Já Serafim et al. (2013) fazem uma observação sobre os estudos da área. Segundo eles, o fato da maior parte das publicações e debates sobre o tema ser de origem anglo-saxã, pode gerar incompreensões semânticas, devido a diferenças culturais. Eles explicam que a terminologia “creative industries”, de origem inglesa, pode ser traduzida no Brasil como “indústrias criativas”. Contudo, o termo no inglês significa "setor”, ou seja, a cadeia de empresas que realizam uma determinada atividade produtiva. Talvez, isso explique o fato de

REAd | Porto Alegre - Edição 82 - N 3 - setembro/dezembro 2015 - p. 659-688 
Machado (2009) salientar que entre o uso de economia criativa, ou da cultura e indústria criativa, a preferência da maioria dos profissionais parece recair sobre os dois primeiros termos, sob a justificativa de que ultrapassariam o "paradigma da chaminé”, implícito no termo indústria, mesmo não havendo diferença significativa entre os termos.

Pratt e Hutton (2013) explicam essa atenção da comunidade internacional devido às enormes potencialidades e evidentes impactos do ponto de vista do desenvolvimento que a economia criativa encerra para os países menos desenvolvidos. A UNCAT $(2008,2010)$ coloca a economia criativa como forma de impulsionar o crescimento econômico e representar uma alternativa para o desenvolvimento, especialmente por ter como matériaprima base a criatividade, e poder utilizar características culturais e sociais de cada país/região como vantagens no desenvolvimento, e produção de bens e serviços únicos. Para isso acontecer, a FIRJAN (2012) destaca a atuação das empresas da cadeia produtiva, que compreende os ciclos de criação, produção e distribuição de bens e serviços que usam criatividade e capital intelectual como insumos primários. Segundo a UNCTAD (2008), o núcleo da Economia Criativa é compreendido por quatro divisões de atividades e seus setores:

1) Núcleo do patrimônio material e imaterial: expressões culturais tradicionais como artesanato, festas populares, celebrações, cultura popular; equipamentos culturais, tais como sítios históricos; e espaços culturais, a exemplo de museus, livrarias, teatros e exposições.

2) Núcleo das artes: artes performáticas, a música, a dança, o teatro, a ópera e o circo, por exemplo; e artes visuais como pintura, escultura, fotografia e antiguidades.

3) Núcleo da Mídia (produção de conteúdo): editoras e mídia impressa, como livros, imprensa e outras publicações; e audiovisual, a exemplo do cinema, TV, vídeo e rádio.

4) Núcleo da Criatividade Aplicada: design - de interiores, gráfico, moda, joias, brinquedos, móveis e objetos, serviços criativos como arquitetura, publicidade, pesquisa e desenvolvimento criativos, recreação, “edutenimento" - termo que funde educação e entretenimento e oferece inúmeras oportunidades de futuro; e novas mídias, como software, vídeo game e conteúdos digitais.

No que compete ao tipo de empresa atuante no setor, a UNCAT (2010) aponta que esta é, em grande parte, de pequeno e médio porte, com dificuldades em obter financiamento para seus projetos, pois aparentemente são mais arriscados que em outros ramos. Já Pratt e Hutton (2013) ressaltam para o viés urbano da economia criativa. Eles indicam que essa

REAd | Porto Alegre - Edição 82 - N 3 - setembro/dezembro 2015 - p. 659-688 


\section{Felipe Carvalhal \& Henrique Muzzio}

associação de concentração da indústria criativa e primazia urbana é, naturalmente, um benefício para as cidades em questão, mas também configura um dilema político na reprodução de desenvolvimento, emprego e renda com disparidades inter-regionais. Outro ponto que eles chamam atenção é que o glamour, conveniência e imagem jovial do trabalho criativo obscurece muitas características negativas, e que apesar de a mídia mostrar esse profissional como sendo socialmente liberal, tolerante e mente aberta, a dura realidade mostra que essa é uma das forças de trabalho mais elitistas e não representativa de todos os setores.

Diante desta abordagem, cabe destacar que, para os fins desta pesquisa adotar-se-á o conceito de indústrias criativas promovido pelo DCMS - aquelas que possuem sua origem na criatividade, habilidade e talento individuais e que têm potencial para geração de empregos e riquezas por meio da geração e exploração da propriedade intelectual - para definir o termo economia criativa. E compreende as empresas dessa economia como aquelas que fazem parte das atividades e setores dos núcleos criativos traçados pela UNCAT (2008).

\section{LIDERANÇA}

Compreender a liderança constitui umas das mais antigas tarefas humanas. Por volta de 2.300 a.C, os egípcios, especialmente Ptahhatep, registrava o primeiro escrito sobre o tema. Para ele, este fenômeno resulta de algo transcendental ao ser humano e designa qualidades superiores (TECCIO et al. 2010). Um dos mais complexos e multifacetados fenômenos, vem sendo estudado por diversas áreas do conhecimento, variando desde gestão, psicologia, sociologia, ciências políticas, administração pública, educação em administração, além de inúmeras matérias jornais e revistas (DORIA, PEREIRA, 2007; HANASHIRO et al. 2005).

A partir do século XIX os estudos sobre o tema foram organizados de forma sistemática. Atualmente, existem inúmeras abordagens, perspectivas e definições recorrentes à liderança, contudo, há consenso entre os estudiosos de que liderança revela influência do líder sobre o liderado. De acordo com Carvalhal (2012), até a década de 1970, existiram três grandes movimentos de pesquisas sobre liderança e seus efeitos no contexto organizacional. São eles: a abordagem dos traços, enfatizando as qualidades dos bons líderes, ou seja, aqueles que supostamente promoviam um melhor desempenho por parte de seus liderados; a perspectiva dos estilos de liderança, que se preocupa na descoberta ou validação de determinados comportamentos de liderança; e os enfoques situacionais de liderança,

REAd | Porto Alegre - Edição 82 - Nº 3 - setembro/dezembro 2015 - p. 659-688 


\section{ECONOMIA CRIATIVA E LIDERANÇA CRIATIVA: UMA ASSOCIAÇÃO (IM) POSSÍVEL?}

contemplando os pressupostos das teorias organizacionais contingencialistas e preocupam-se em definir a associação de determinado comportamento de liderança a um contexto específico.

Estudos posteriores, conforme Stoner e Freeman (1999), passaram a investigar o comportamento de líderes que impactam de modo excepcional suas organizações. Esta nova abordagem, percebida após a década de 80, é tratada como "nova liderança”. Segundo Bryman (2004), os estudos que se configuraram como a "nova liderança", diferem essencialmente das abordagens anteriores no que se refere à orientação, uma vez que se baseiam numa representação de líderes como administradores de sentido, e não em termos de um processo de influência. Para Merhi et al. (2008) essa nova abordagem traz consigo a necessidade de revisão, por parte dos líderes, de suas práticas e do entendimento de seu novo papel nas organizações frente a novos atributos indispensáveis a ele, tais como: cooperação, autonomia, trabalho em equipe e inovação; faz-se necessário revisar modelos até então conhecidos e validados. Dentre as diversas abordagens da "nova liderança”, nesse estudo será tratado e utilizado como base de análise a liderança criativa, explanada a seguir.

\section{Liderança criativa}

Criatividade é uma das características mais mencionadas em listas de competências desejáveis para um líder ou profissional em geral. Contudo, Grinberg (2014) questiona o que significa criatividade no mundo corporativo. Para ele, independentemente do que esteja no dicionário, ou até mesmo qual seja o significado etimológico da palavra, no mundo corporativo, criatividade deveria significar a capacidade de apresentar soluções alternativas para problemas conhecidos, e saídas inovadoras para novos problemas. É a partir da criatividade que as pessoas passam a conhecer novas habilidades, das quais não tinham conhecimento, permitindo também o desenvolvimento em suas relações inter e intrapessoais. Amabile (1997) argumenta que a literatura sobre criatividade tem centrado a atenção, especialmente na contribuição do indivíduo para a inovação e a mudança técnica.

Nessa perspectiva, o Modelo de Liderança Criativa (MLC) desenvolvido por Rickards e Moger (2000), focaliza o comportamento do grupo e o gerenciamento da equipe de trabalho, e sugere que a partir da liderança criativa, líderes e liderados podem conseguir elevados níveis

REAd | Porto Alegre - Edição 82 - N 3 - setembro/dezembro 2015 - p. 659-688 


\section{Felipe Carvalhal \& Henrique Muzzio}

de criatividade, inovação em equipes de trabalho, e atingir ou superar as expectativas de desempenho estabelecidas pela organização, com o surgimento de estruturas benignas no grupo, favorecidas por um estilo de liderança participativo e apoiador, que enfatize a mutualidade e a cooperação.

Para a criação desse modelo, Rickards e Moger (2000) utilizaram o processo de formação de equipes baseado no trabalho de Tuckman (1965 apud RICKARDS E MORGAN, 2000) e Tuckman e Jensen (1977 apud RICKARDS E MORGAN, 2000), em que a formação de equipes passa por cinco fases: form (formação), storm (turbulência), norm (normatização), perform (performance) e adjourn (finalização) .Ao analisarem esse processo, eles perceberam que existem barreiras que são inerentes ao mesmo e alteram o desempenho destas equipes. Rickards e Moger (2000) usam o termo "barreira” para indicar um impedimento estrutural ao desenvolvimento da criatividade. Ferreira, Gimenez e Ramos (2005) argumentam que esse é um impedimento relativo, pois a avaliação do desempenho das equipes depende da cultura organizacional e das expectativas em relação à performance. Santos et al (2003) possuem visão semelhante, e veem as barreiras tanto externamente, como pressões do ambiente, quanto internamente, como barreiras socialmente construídas.

A primeira barreira encontrada influencia a formação da equipe e pode impedir que ela se constitua efetivamente. Já a segunda, está relacionada à capacidade de criação e inovação conseguida pelo grupo, configurando uma forte barreira à performance. Ao perceberem estas barreiras para a formação e performance das equipes, Rickards e Moger (2000) advogam que o líder é responsável pela introdução de estruturas benignas que permitirão às equipes superarem. Inácio Júnior e Gimenez (2004) destacam que a atenção dada pelos autores a este tipo de estrutura, associada ao processo criativo em equipe, está em sintonia e de acordo com os trabalhos que mostram a importância da posse de uma base compartilhada de entendimento, princípios e conhecimento.

A Liderança Criativa tem como peça chave, o papel do líder em trabalhar de maneira que altere o comportamento da equipe de inaceitável, para aceitável, e, posteriormente, para superior, através da introdução das “estruturas benignas”, enfatizando a cooperação, e não a coerção, e também a mutualidade, ou seja, situações que beneficiam o grupo e o líder ao mesmo tempo. Essas estruturas benignas são formadas por sete fatores de equipes criativas identificados por Rickardse Moger (2000), conforme verifica-se no quadro a seguir.

REAd | Porto Alegre - Edição 82 - N 3 - setembro/dezembro 2015 - p. 659-688 
ECONOMIA CRIATIVA E LIDERANÇA CRIATIVA: UMA ASSOCIAÇÃO (IM)

POSSÍVEL?

Quadro 1 - Os Setes Fatores de Equipes Criativas

\begin{tabular}{|l|l|}
\hline \multicolumn{1}{|c|}{ Fatores } & \multicolumn{1}{c|}{ Características } \\
\hline $\begin{array}{l}\text { Plataforma de } \\
\text { entendimento }\end{array}$ & $\begin{array}{l}\text { Os membros da equipe entendem e respeitam os pontos de vistas uns dos outros; a equipe } \\
\text { compartilha conhecimento, crenças, valores e conviç̧ões. O líder explica as atividades para } \\
\text { sua equipe. Esses elementos incluem a plataforma de entendimento da qual novas ideias se } \\
\text { desenvolverão. }\end{array}$ \\
\hline $\begin{array}{l}\text { Visão } \\
\text { compartilhada }\end{array}$ & $\begin{array}{l}\text { Os membros da equipe compartilham senso de propósito e responsabilidades que motivam } \\
\text { e sustentam o progresso da equipe. Eles também levam junto visões poderosas e } \\
\text { significativas sobre o futuro. }\end{array}$ \\
\hline Clima & $\begin{array}{l}\text { O líder destaca a importância de um clima positivo no trabalho, procurando que os } \\
\text { membros da equipe confiam uns nos outros e compartilham uma positiva e acolhedora } \\
\text { abordagem para estimular a criatividade no trabalho. }\end{array}$ \\
\hline Resiliência & $\begin{array}{l}\text { O líder da equipe acentua o princípio de buscar perspectivas alternativas ao lidar com as } \\
\text { expectativas frustradas, tornando os membros de sua equipe flexíveis com as frustrações e } \\
\text { obstáculos. }\end{array}$ \\
\hline $\begin{array}{l}\text { Ideias } \\
\text { próprias }\end{array}$ & $\begin{array}{l}\text { Os esforços da liderança são feitos para o compromisso de construir ideias. Uma equipe } \\
\text { criativa cria e sustenta novas e valorosas ideias de problemas relacionadas a tarefa, de } \\
\text { maneira que é dada mais atenção aquelas percebidas como abertas ao comprometimento de } \\
\text { toda a equipe. }\end{array}$ \\
\hline $\begin{array}{l}\text { Ativação em } \\
\text { rede }\end{array}$ & $\begin{array}{l}\text { Membros da equipe são bons em se comunicarem com pessoas de fora da equipe, trocando } \\
\text { ideias e oferecendo apoio mútuo. A liderança criativa permite que sua equipe, através de } \\
\text { uso de network, capture habilidades, conhecimento e recursos para a resolução de } \\
\text { problemas da equipe. }\end{array}$ \\
\hline $\begin{array}{l}\text { Aprendizado } \\
\text { vindo da } \\
\text { experiência }\end{array}$ & $\begin{array}{l}\text { O líder estimula o aprendizado, possibilitando crescimento, mudança, adaptação e solução } \\
\text { de problemas de forma criativa. Os membros da equipe são orientados em direção do } \\
\text { aprendizado vindo de suas próprias experiências, permitindo assim que estes sintam-se mais } \\
\text { dispostos a ousar. }\end{array}$ \\
\hline
\end{tabular}

Fonte: Adaptado (RICKARDS; MOGER, 2000; FERREIRA; GIMENEZ, 2004)

A maior ou menor presença desses fatores faz com que barreiras existentes que impedem a inserção ou o desenvolvimento das "estruturas benignas" no grupo sejam quebradas. O resultado permite a classificação das equipes em uma entre três categorias: equipes vindas do inferno, equipes padrão e equipes dos sonhos, quanto maior o resultado, melhor a classificação.

Poucas pesquisas com este modelo foram realizadas. Gallon e Ensslin (2008) mostraram que todas as equipes de trabalho foram consideradas dos sonhos. No estudo delas, os fatores que mais se destacaram foram o Clima e Ideias próprias, sendo o de menor visibilidade, a Visão compartilhada. Já os estudos de Santos et al (2003), Inácio Júnior e Gimenez (2004) e Ferreira, Gimenez e Ramos (2005), não permitiram tal observação, e apenas apontaram para uma associação positiva entre a liderança criativa e o potencial.

\section{PROCEDIMENTOS METODOLÓGICOS}

REAd | Porto Alegre - Edição 82 - N 3 - setembro/dezembro 2015 - p. 659-688 
Tendo em vista os objetivos do estudo, foi realizada uma pesquisa de natureza qualitativa, a qual adota a realidade como uma construção social, evidenciada em meio a observação de qualidades, significados e valores conferidos a objetos e fenômenos, por indivíduos ou grupos sociais em seu contexto histórico e sociocultural, permitindo assim, uma melhor compreensão e perspectiva integrada (CRESWELL, 2010; FLICK, 2009; GODOY, 1995). A estratégia de pesquisa utilizada é a de estudo de casos múltiplos, a qual, conforme Yin (2001), tem por objetivo analisar com profundidade um fenômeno. A importância de realizar esta pesquisa, como estudo de casos múltiplos, parte da premissa de que existem poucos estudos no Brasil que analisam a liderança criativa e a economia criativa, levando a acreditar que mais de uma empresa pesquisada poderia trazer informações complementares sobre um assunto ainda pouco explorado. O principal critério adotado para a escolha dos casos foi a acessibilidade. Foram analisados três casos com gestores de empresas da economia criativa, situadas na cidade de Recife-PE, cujos negócios estivessem funcionando há, no mínimo, seis meses, e que estes gestores tivessem pelo menos um liderado sobre seu exercício. Os dados deste estudo foram coletados por meio de entrevistas pessoais semiestruturadas, em profundidade por meio de roteiro de entrevistas, cuja duração média girou em torno de 55minutos. As entrevistas foram gravadas, e, posteriormente, transcritas e analisadas com a adoção da técnica de análise de conteúdo, que visa captar as características essenciais, os significados, as convergências e as divergências dos conteúdos das entrevistas (BARDIN, 2008).

Para facilitar a comparação das evidências empíricas com os preceitos teóricos, as categorias analíticas balizadoras do estudo compreendem os fatores da liderança criativa expostos no quadro 01. Contudo, além deles, será dado destaque também para a criatividade e a produtividade das equipes. No que tange à criatividade, procurar-se-á saber o que impede ou atrapalha, e o que contribui para a mesma, além de questionar sobre o entendimento que os entrevistados possuem da mesma, e ainda, no que se refere a um ambiente criativo, e sua influência para a criatividade. Já em relação à produtividade, foi questionado sobre o desempenho das equipes, os meios de monitoramento e a frequência dos mesmos, bem como o papel do líder nisso. Além disso, será feita uma caracterização da empresa e do entrevistado e sua equipe, visando um melhor posicionamento do leitor no trabalho. Faz-se necessário ressaltar, também, que nesta pesquisa foi feita uma adaptação do modelo e instrumento REAd | Porto Alegre - Edição 82 - N 3 - setembro/dezembro 2015 - p. 659-688 
ECONOMIA CRIATIVA E LIDERANÇA CRIATIVA: UMA ASSOCIAÇÃO (IM)

POSSÍVEL?

proposto por Rickards e Moger (2000), de natureza quantitativa e esta, por sua vez, adota uma linha qualitativa.

\section{DESCRIÇÃO E ANÁLISE DOS CASOS}

Devido à limitação de espaço neste trabalho, optou-se por fazer uma abordagem geral dos três casos pesquisados, com a finalidade, a priori, de situar o leitor para uma compreensão da análise comparativa futura sobre os fatores da liderança criativa e os outros aspectos.

\subsection{Descrição dos casos}

\subsubsection{Caso 01: O Coworking}

O entrevistado tem 27 anos, e é Mestre em Engenharia Nuclear, com graduação em física. Este não é seu primeiro empreendimento, tendo há quase 10 anos aberto uma empresa na área de arquitetura, a qual ainda está em operação e é gerida pelo irmão. Ele nos conta um caso curioso, onde, em 2010, após fazer um curso de capacitação empreendedora, percebeu que não era aquilo que “queria da vida”. Diante disso, pediu demissão da própria empresa e começou a tocar alguns projetos pessoais. Nesse meio tempo, começou a fazer parte da equipe de facilitadores do curso que participou, da qual ainda pertence, além disso, tornou-se produtor e organizador de eventos.

O seu negócio, funciona desde setembro de 2013, possui quatro funcionários e conta mais três sócios. É uma rede mundial, um tipo de franquia, presente em mais de 60 países do mundo. Em suma, é um espaço de trabalho compartilhado que se distingue de negócios semelhantes pelos valores compartilhados. Essa rede abarca mais de 7000 membros espalhados nos cinco continentes, e em Recife, possui mais de 160 membros ativos, em sua maioria start-ups, compostas por duas a cinco pessoas.

Sobre a equipe que é responsável por gerir, o entrevistado diz que é formada por gestores de capital de risco, dentre outras, pessoas ligadas à comunicação e marketing. Declara que a formação acadêmica dessas pessoas é, de certa forma,“um pouco irrelevante para o negócio em si, o que precisa é que essas pessoas sejam desenroladas. O resto elas aprendem.”. Ele afirma que procura dar o máximo de autonomia e liberdade para sua equipe,

REAd | Porto Alegre - Edição 82 - N 3 - setembro/dezembro 2015 - p. 659-688 


\section{Felipe Carvalhal \& Henrique Muzzio}

ficando de suporte e apoio para o que for preciso, ao invés de ficar no pé e cobrando o tempo todo.

\subsubsection{Caso 02: O Ateliê}

A entrevistada tem 50 anos, é formada em publicidade, mas ainda jovem chegou a cursar engenharia civil, do qual desistiu logo no início. Relata que a formação em publicidade contribui para seu trabalho, de modo que ela começou a entender os desejos de suas clientes. Quem lhe despertou o desejo de ser empreendedora foi uma amiga, ainda na época da faculdade de engenharia, onde no período de férias, foi convidada por essa para fazer parte da equipe de sua confecção, e ficou encantada como mundo da moda. Quando estava prestes a voltar às aulas conversou com o pai, mostrou o desejo de ter o negócio próprio neste ramo e afirmou que não queria continuar o curso, recebendo o total apoio dele.

A empresa criada quando ela tinha 21 anos, conta com 12 funcionários. Desde sua fundação sofreu alterações no foco do negócio. No período da época do Governo Collor, a inserção de produtos importados na indústria têxtil, a fez repensar seu negócio, voltando-o para o mercado de alta costura. Devido a carência de cursos na cidade do Recife-PE, entre outros fatores, ela foi à São Paulo onde visitou brechós e descobriu como se fazia tais peças, como destaca em seu depoimento:

"Eu fui à São Paulo [...] fui a brechós comprei essas roupas e desmanchei para entender o que tinha dentro. Era a única maneira de eu aprender. [...] Eu não sabia nem o nome daqueles tecidos. Eu saí na 25 da vida (em referência a famosa rua 25 de março em São Paulo) perguntando nas lojas.

A entrevistada revelou que precisou abandonar a confecção de roupas normais - em referência a roupas de uso comum - para começar a focar exclusivamente no mercado de alta costura. Nessa época, demitiu todas as suas funcionárias, e mudou de local. Pouco tempo depois, com o negócio estabilizando, recontratou-as, e contratou outras. Atualmente, seu sentimento é de um pouco de desânimo com o mercado atual, não no que tange aos negócios em si, mas no fato de não poder usar a criatividade como gostaria, pois boa parte das clientes já vem com uma ideia fechada sobre o que deseja, e principalmente as jovens, que possuem

REAd | Porto Alegre - Edição 82 - Nº 3 - setembro/dezembro 2015 - p. 659-688 
ECONOMIA CRIATIVA E LIDERANÇA CRIATIVA: UMA ASSOCIAÇÃO (IM)

POSSÍVEL?

medo de ousar, de fazer algo diferente, revelando que até considerou a possibilidade de fechar o negócio, dado essa situação.

4.1.3 Caso 03: O Estúdio de Design

A entrevistada é formada em design gráfico, está cursando mestrado em administração e possui 38 anos, também exerce a função de professora em instituições de ensino superior. Sempre atuou na área de design, já teve outra empresa quando tinha 24 anos, da qual foi sócia por 10 anos, em paralelo a isso, trabalhou em um jornal de grande circulação na cidade de Recife-PE. Isso permitiu que ela enxergasse a relação patrão empregado, visto que, em sua empresa era líder, enquanto na outra, liderada.

Essa nova empresa, um estúdio de design, criada em sociedade com uma amiga, está a um ano no mercado, e as atividades são realizadas em espaços de coworking e home office. Fundada por seu perfil empreendedor, visto que tinha deixado a outra empresa pouco tempo antes, conta com uma equipe de três designs, sendo que dois trabalharam com ela no outro escritório. Esse novo ambiente de trabalho é novidade para ela, pois nunca trabalhou dessa maneira, e argumenta que o profissional criativo está buscando isso para ter mais liberdade de horário, contudo, alega que o controle fica restrito, visto que os encontros pessoais não são diários, e não saber se realmente a pessoa está fazendo aquilo ou não.

Percebemos uma convergência ao que aponta a UNCAT (2010), em se tratando do porte das empresas, onde a maioria é de pequeno e médio porte, semelhante às empresas pesquisadas.

\subsection{Análise comparativa}

A seguir serão explanados os fatores que compõe a liderança criativa e os outros pontos pesquisados na entrevista.

No que tange à plataforma de entendimento, o objetivo é fazer com que novas ideias se desenvolvam, para isso, os membros da equipe precisam entender e respeitar os pontos de vistas uns dos outros, além de compartilharem conhecimento, crenças, valores e convicções. O papel do líder é explicar as atividades para sua equipe (RICKARDS; MOGER, 2000; FERREIRA; GIMENEZ, 2004).

REAd | Porto Alegre - Edição 82 - N 3 - setembro/dezembro 2015 - p. 659-688 


\section{Felipe Carvalhal \& Henrique Muzzio}

Nesse aspecto, foi possível perceber que o entrevistado 01 está preocupado em criar um ambiente propício ao desenvolvimento de novas ideias. Ele deixa claro o que precisa ser feito, o prazo e o resultado esperado, ficando à disposição de sua equipe para possíveis dúvidas e apoio. Uma ferramenta que ele utiliza são as reuniões periódicas que realiza, semanal, mensal, trimestral e anualmente. Nelas são tratadas, além de questões de trabalho, questões pessoais, a fim de gerar maior interação entre a equipe, e fazer com que seus membros possam se conhecer e entender um ao outro, para que assim possam se ajudar. Para ele, transparência total e conversa, são itens essenciais para criar um bom entendimento dentro de sua equipe, com vistas a um ambiente de colaboração, e não de competição.

A entrevistada 02, diz que procura conversar pessoalmente com suas funcionárias e mostra interesse pela vida delas, se reúnem em datas comemorativas. Contudo, ela revela que tem dificuldades em fazer reuniões com sua equipe, por se considerar tímida. Para que cada um tenha bom entendimento das necessidades do outro, busca fazer intercâmbios nas atividades, o que acaba possibilitando que elas se conheçam melhor e aprendam umas com as outras, e não que uma, em determinada função, se enxergue melhor.

Já a entrevistada 03, revela que através dos encontros semanais com a equipe, e por meio da intimidade que já possui devido a experiências anteriores, há uma transmissão de valores e das crenças de cada um, potencializado em ocasiões como aniversário, festas comemorativas e coisas deste tipo. No que tange a fazer com que sua equipe tenha um bom entendimento das diferenças e necessidades de cada um, ela comenta que é tarefa difícil, dada as diferenças de cada pessoa, conforme depoimento:

"Isso é muito difícil. Porque as pessoas são diferentes. Elas podem ser parecidas, mas elas nunca vão ser iguais. Nem sempre elas têm a mesma atitude e pensamentos. [...] mas existem certas regras que não podem ser requebradas.”

Observa-se que apenas o entrevistado 01 consegue chegar ao que seria esperado de um líder criativo, havendo uma propagação dos valores, crenças de cada um e da empresa para que fosse possível chegar a um entendimento comum, visando o surgimento de ideias para a organização. Contudo, percebe-se que as demais entrevistadas se esforçam para tal, mesmo diante de impedimentos pessoais.

Em relação à visão compartilhada, o desafio do líder é criar nos membros da equipe que compartilham, um senso de propósito e responsabilidades que motivam e sustentam o

REAd | Porto Alegre - Edição 82 - N 3 - setembro/dezembro 2015 - p. 659-688 


\title{
ECONOMIA CRIATIVA E LIDERANÇA CRIATIVA: UMA ASSOCIAÇÃO (IM) POSSÍVEL?
}

progresso dela, fazendo com que seus membros tenham visões poderosas e significativas sobre o futuro (RICKARDS; MOGER, 2000; FERREIRA; GIMENEZ, 2004).

Pode-se perceber que o entrevistado 01 deixa nítido para sua equipe quais os planos da empresa, e qual o papel de cada para que isso possa ser alcançado, conforme observado em seu depoimento:

\begin{abstract}
“A gente tem um plano de 10 anos [...] e a gente sempre repassa essa meta para equipe e qual é o propósito da empresa. [...] para garantir que as pessoas lembrem por que é que elas estão aqui. O que elas têm que fazer no final das contas, qual o objetivo nobre do trabalho que elas estão desenvolvendo. Se for preciso que meu gerente tenha que trocar uma lâmpada, ele tem que entender que não tá trocando a lâmpada, ele tá criando um ambiente para quem está trabalhando possa desenvolver a sua mais alta performance.
\end{abstract}

Já a gestora e fundadora do ateliê, utiliza a metáfora da corrente, onde explica, nas poucas reuniões que faz com sua equipe, que cada uma é um elo, que não existe mais fraco ou mais forte, mas que todos fazem parte de uma equipe, com um mesmo objetivo. Confessa uma carência no repasse dos planos para sua equipe: "Eu acho que eu nem tenho passado isso muito para minhas funcionárias, talvez eu até precise. Eu tenho meus planos, mas eu não tenho passado isso.”

A entrevistada 03 revela que é complicado criar um propósito compartilhado, principalmente no meio criativo, onde, segundo ela, há uma disputa de ego, e as pessoas são meio autodidatas, sendo difícil fazer com que estas compartilhem dos mesmos pensamentos e ideias. Porém, mesmo diante dessa realidade, ela procura deixar claro para sua equipe, através das reuniões semanais, o que deve ser feito em relação ao trabalho, quais os objetivos da empresa e da equipe.

Aqui, enxergamos uma deficiência da entrevistada 02 em passar os objetivos da empresa, bem como destacar a importância de um propósito compartilhado para sua equipe, ficando apenas em conversas informais e um teor mais operacional do trabalho. Percebemos uma diferenciação nesse sentido, facilitada pelas reuniões semanais, mas devido ao pouco convívio diário, e as particularidades de seus liderados, isso não chega a criar um sentido, um propósito. O que acontece na organização do entrevistado 01, onde vemos uma preocupação em fazer com que todos saibam o que estão fazendo, e para onde estão indo, bem como o seu papel naquilo.

REAd | Porto Alegre - Edição 82 - N 3 - setembro/dezembro 2015 - p. 659-688 


\section{Felipe Carvalhal \& Henrique Muzzio}

Já sobre o clima, o líder deve destacar a importância de um clima positivo no trabalho, procurando que os membros da equipe confiem uns nos outros e compartilhem uma positiva e acolhedora abordagem para estimular a criatividade no trabalho (RICKARDS; MOGER, 2000; FERREIRA; GIMENEZ, 2004).

Frente a isso, o entrevistado 01 destacou as duas filosofias de seu negócio para se criar um clima amistoso no ambiente de trabalho, ser uma empresa livre de julgamentos e com aceitação incondicional, onde é rechaçado qualquer tipo de preconceito. Ele se vale das reuniões e conversas informais para relembrar isso. Destaca ainda, que provoca o apoio mútuo em sua equipe criando uma interdependência entre os resultados a serem alcançados, onde para que alguém atinja 100\%, será necessário que todos os colegas da equipe também alcancem esse patamar.

A entrevistada 02 fala que para criar um clima agradável em sua equipe, procura prezar pelo respeito entre funcionários, dela para com sua equipe e o contrário, tentando resolver qualquer problema através do respeito. Para ela, a verdade sobre os fatos é a principal prática para criar esse ambiente de confiança. Ela afirma que enxerga sua equipe unida, por observar fatores externos à empresa, como por exemplo, quando suas funcionárias vão a eventos da colega de trabalho, fazendo atividades juntas.

Em relação a este fator, a entrevistada 03 diz que mesmo com modelo de trabalho diferenciado, há a busca para se criar um ambiente acolhedor, para isso, usa-se das redes sociais e meios virtuais, como facebook, whatsapp, Skype, mas relata que não é a mesma coisa que se estivesse num mesmo espaço diariamente. Já para criar um ambiente de confiança mútua, ela utiliza a transparência, e percebe que os membros de sua equipe se dão apoio, como visto em sua fala:

Tudo que a gente conversa, sobre todos os trabalhos é exposto no grupo que a gente tem (em referências aos grupos no whatsapp e facebook). Então, mesmo que não seja um trabalho que aquela pessoa esteja envolvida, mas ela sabe o que está acontecendo [...] não é nada escondido [...] E quando há necessidade eles buscam um ao outro pra poder ajudar em algum tipo de atividade que eles não estão conseguindo fazer.

Chegamos a um fator de comum entendimento dos entrevistados. Todos buscam criar um ambiente e trabalho onde seus liderados possam se sentir bem. Destacam valores como trabalhar como respeito, a verdade, serem livres de preconceitos, transparência e apoio mútuo. E criam-se mecanismos para que eles busquem esse apoio, a exemplo da troca de funções, ou a interdependência destas.

REAd | Porto Alegre - Edição 82 - Nº 3 - setembro/dezembro 2015 - p. 659-688 


\section{ECONOMIA CRIATIVA E LIDERANÇA CRIATIVA: UMA ASSOCIAÇÃO (IM) POSSÍVEL?}

No quesito ideias próprias, os esforços do líder são feitos para o compromisso de construir ideias, fazendo com que sua equipe crie e sustente novas e valorosas ideias de problemas relacionadas a tarefa, de maneira que é dada mais atenção aquelas percebidas como abertas ao comprometimento de toda a equipe (RICKARDS; MOGER, 2000; FERREIRA; GIMENEZ, 2004).

Nesse aspecto, foi observado que entrevistado 01 procura estimular a construção de ideias por meio de um ambiente que permita que os membros da equipe tragam ideias, coisas e novas iniciativas. A hora do chá, criado pelos próprios membros, é um momento que pode contribuir para a elaboração de ideias compartilhadas, visto que, segundo o entrevistado, nessas ocasiões, sempre acontecem conversas estimulantes e inspiradoras. Para ele, sua equipe se engaja para fazer com que as ideias deem certo. Conta que premia com pelo menos uma cerveja, o funcionário que lhe apresentar uma boa ideia.

A entrevistada 02 afirma que percebe sua equipe preocupada em trazer novas ideias, pois sempre que elas veem algo diferente mostram para ela. Confessa ainda, que frequentemente estimula isso nelas, mostrando coisas diferentes. Já a entrevistada 03, fala que nem sempre sua equipe está preocupada em trazer novas ideias, para ela há uma carência de proatividade: “eles acabam meio que esperando bastante”. Revela que alimenta, e fica feliz quando um funcionário traz uma ideia nova, e, caso não possa ser usada naquele momento, deixa de salvaguarda para o momento oportuno.

Vislumbramos, diante desse fator, que os líderes estimulam seus liderados a colaborar com novas ideias, em especial, os entrevistados 01 e 02. Todos ficam contentes quando seus funcionários chegam com uma ideia, e há até o caso de ser agraciado com uma cerveja, algo simbólico, que demonstra um ambiente que foge do tradicional.

Em se tratando da resiliência, o líder acentua o princípio de buscar perspectivas alternativas ao lidar com as expectativas frustradas, tornando os membros de sua equipe flexíveis com as frustrações e obstáculos (RICKARDS; MOGER, 2000; FERREIRA; GIMENEZ, 2004).

Nesse ponto, o entrevistado 01 aponta que isso o remete aos valores pregados em seu negócio, não desistir nunca. Percebe sua equipe unida para a resolução de problemas inesperados, o papel dele, nesse aspecto, é como de um observador, procurando não influenciar no agir deles, com o intuito de estimular, a autonomia e a independência. Contudo,

REAd | Porto Alegre - Edição 82 - N 3 - setembro/dezembro 2015 - p. 659-688 


\section{Felipe Carvalhal \& Henrique Muzzio}

deixa claro que está ali para ajudar quando for preciso. Comenta também, que toda e qualquer conquista é celebrada, vista o esforço e sacrifício exigidos.

A entrevistada 02, procura fazer com que sua equipe mantenha a calma, e veja quais são as soluções possíveis, pois não é preciso fazer alarde. Vê sua equipe unida para resolver problemas, mas revela que tem um papel passivo nisso, apenas agradecendo. Tenta tranquilizar sua equipe frente às frustrações, e seguir em frente, tentando não cometer o erro que provocou aquilo novamente.

Já a entrevistada 03, afirma que é preciso ter resiliência para superar os obstáculos, e procura conversar com a equipe sobre a situação, para resolver o que seja necessário. Percebe sua equipe unida para lidar com problemas inesperados, como revelado em sua fala: "Eu percebo que eles procuram uns aos outros, antes de nos procurar”. Quanto a superar as frustrações, ela retoma para a conversa como principal ferramenta, fazendo uma análise do que aconteceu para trabalhar a situação.

Os líderes se esforçam para fazer com que sua equipe mantenha-se centrada na resolução dos problemas, e não se desesperem em tal situação. Buscam conversar e discutir o que aconteceu, o que pode/deve ser feito para que aquilo não volte a acontecer. Aqui, percebemos o valor do diálogo, e a abertura e confiança nessa relação.

Quando o assunto é a ativação em rede, o líder possui como obrigação fazer com que os membros de sua equipe sejam bons em se comunicarem com pessoas de fora da equipe, troquem ideias entre si, e ofereçam apoio mútuo, sempre visando a solução dos problemas da equipe (RICKARDS; MOGER, 2000; FERREIRA; GIMENEZ, 2004).

Aqui, o entrevistado 01 garante que estimula que seus funcionários mantenham contatos com pessoas externas à organização, ou com usuários da rede de coworking interna do negócio do qual faz parte. Incentiva que seus liderados participem de uma comunidade de prática, onde há encontros quinzenais online. E se sente feliz quando membros de sua equipe utilizam contato externo para resolver problemas do negócio e/ou trazer ideias, conforme seu depoimento:

"Eu fico feliz, porque acho que a rede de contato tem que ser usada mesmo. A partir do momento eu vejo um funcionário meu utilizando contatos pessoais externos para resolver problemas da empresa significa que esse cara tá no mínimo comprometido. Isso tem que ser estimulado tem que ser valorizado.

REAd | Porto Alegre - Edição 82 - Nº 3 - setembro/dezembro 2015 - p. 659-688 


\section{ECONOMIA CRIATIVA E LIDERANÇA CRIATIVA: UMA ASSOCIAÇÃO (IM) POSSÍVEL?}

A entrevistada 02 incentiva que sua equipe mantenha contatos com pessoas externas. Inclusive fala que algumas de suas funcionárias trabalham em outras confecções, e sempre trazem novas soluções e ideias. Já a entrevistada 03, afirma que incentiva que sua equipe mantenha contatos externos, seja através de treinamentos, cursos, palestras. E reage de forma positiva quando seus membros utilizam contatos externos para resolver problemas internos, mas faz uma ressalva, como visto em seu depoimento:

"Eu não vejo nenhum problema. Contanto que essa pessoa [..] não vai se intrometer no resultado da empresa. Ela vai servir como algum tipo de apoio para ele tá buscando para melhorar o próprio trabalho dele.

Há um estímulo por parte da liderança para que seus liderados busquem ativar o network, seja através de comunidades de práticas da própria organização, ou com treinamentos e eventos, ou ainda com trabalhos externos. Podemos perceber, graças à natureza do trabalho e do ambiente instalado, uma maior facilidade do entrevistado 01 nesse aspecto.

Quanto ao aprendizado vindo da experiência, o líder precisa estimular o aprendizado, com o intuito de possibilitar crescimento, mudança, adaptação e solução de problemas de forma criativa. Os membros da equipe são orientados em direção ao aprendizado vindo de suas próprias experiências, permitindo assim, que estes se sintam mais dispostos a ousar (RICKARDS; MOGER, 2000; FERREIRA; GIMENEZ, 2004).

No que tange a esse fator, o entrevistado 01afirma que promove espaços de discussões do comportamento da equipe, as reuniões já citadas aqui. Relata que procura fazer com que seus funcionários se sintam bem, como parte de um conjunto, ou segundo as palavras dele “partes de uma família mesmo e não que estão soltos”. Utiliza esses espaços para discutir construtivamente os erros cometidos, e relembra que lá é espaço livre de julgamento, onde o foco está em responder a questões do tipo, o que foi que aconteceu para que aquilo fosse atingido, o que poderia ter sido feito para evitar, e o que fazer a partir de agora para que não aconteça novamente. Inclusive, comenta que, se for preciso, volta para a operação e ajuda no que for necessário.

De modo contrário, a entrevistada 02 afirma que não promove esses espaços de discussão do comportamento, mas já tentou, como apresenta em sua fala: “Não. A gente não tem. Eu já tentei fazer isso e não deu muito certo, deu briga.”. Relata ainda que, a equipe nem sempre discute construtivamente sobre os erros cometidos, e confessa que, reage de forma

REAd | Porto Alegre - Edição 82 - Nº 3 - setembro/dezembro 2015 - p. 659-688 


\section{Felipe Carvalhal \& Henrique Muzzio}

reativa aos erros, procurando mostrar o que ocasionou aquilo, para que não aconteça novamente.

A entrevistada 03 argumenta que nessa nova concepção de trabalho, não promove espaços de discussões sobre o comportamento da equipe, com ressalvas aos momentos em que eles se encontram, mas cujo foco não está em fazer isso, a não ser em que ocorra algo que justifique. Ela diz que quando faz isso, percebe uma reatividade da equipe, como se fosse uma bronca ou coisa do tipo.

Aqui encontramos mais uma vez disparidades entre os entrevistados. Há uma notória congruência das ações do entrevistado 01 com o que é requerido de uma liderança criativa. E, no caso da entrevistada 02, há certo receio em retomar espaços para discussões, devido experiências não satisfatórias. Enquanto que a entrevistada 03 evita fazê-lo, pois há uma interpretação equivocada sobre a intenção de tal fato.

Sobre o aspecto produtividade, o entrevistado 01 diz considerar sua equipe produtiva, pelo fato de que, até agora, todos os resultados foram atingidos. O monitoramento sistemático é visto como peça fundamental para alcançar os patamares de desempenho esperado, acontecendo nas reuniões periódicas. O papel dele é “limpar o terreno” para que sua equipe possa desenvolver o trabalho em seu melhor potencial.

A entrevistada 02 considera sua equipe produtiva, mas de certo modo, um pouco lenta. O que encara aqui uma perspectiva de que a mesma não está trabalhando em sua mais alta performance. Apesar disso, acredita na qualidade dos produtos que sua equipe faz, em $90 \%$ dos casos, e para monitorar o progresso em tempo real, criou um checklist para a equipe conferir quando as peças ficam prontas, mas sempre esse é utilizado, fazendo que ele reforce o pedido.

A entrevistada 03 também acredita que sua equipe é produtiva, visto a divisão dos trabalhos pelas competências de cada um, aumentando o desempenho. Para atingir os padrões esperados, utiliza reuniões e acredita que o trabalho deles é de qualidade.

Há consenso quanto à produtividade das equipes dos liderados, com destaque para o uso do monitoramento sistemático, seja através das reuniões, ou diariamente. Fazendo uso desta, inclusive, para acompanhar a qualidade de entrega dos produtos/serviços.

Já em relação à criatividade, o entrevistado 01 compreende esta como sendo a capacidade de resolver problemas com soluções simples, de forma elegante. Para ele, o que contribui para que a criatividade seja aflorada é a liberdade e autonomia dos funcionários,

REAd | Porto Alegre - Edição 82 - Nº 3 - setembro/dezembro 2015 - p. 659-688 


\section{ECONOMIA CRIATIVA E LIDERANÇA CRIATIVA: UMA ASSOCIAÇÃO (IM)}

\section{POSSÍVEL?}

como também o contato com outras pessoas. Do lado contrário, aponta que a criatividade é comprometida pela falta de autonomia dos funcionários e a negação constante que essas pessoas possam ter sobre suas ideias, conforme apresentado em sua fala:

"O que compromete a criatividade é justamente a falta de autonomia dos funcionários. O fato de estar sempre dizendo não para eles. Toda vez que o funcionário chega com uma ideia nova você diz não, você acaba podando a criatividade, matando mesmo a criatividade dessa pessoa. Aqui a gente tenta sempre não dizer não, mas perguntar diga mais, elabore mais...”

A entrevistada 02 vê a criatividade como fazer coisas novas, coisas diferentes, mas diz que nem todas as funcionárias podem ser criativas, devido à função exercida, e cita a costureira. Para ela, fatores que afloram à criatividade são o relacionamento interpessoal com as outras pessoas, não ter preconceito com nada, e destaca a liberdade para criar, para fazer o diferente. Incentiva isso mostrando coisas diferentes, que para sua equipe, pareceriam absurdas. Em relação aos que comprometem, aponta para o bem-estar da pessoa e a falta dessa liberdade.

Já a entrevistada 03 compreende por criatividade como "pensar fora da caixa, sair do convencional”. Diz que fatores como o tempo, prazos curtos, volume de trabalho e o cansaço físico e mental comprometem a criatividade. De modo oposto, acredita que estar informado, conhecer a forma que outros fazem, e procurar ver o mundo de modo diferente, é o que pode aflorar a criatividade, tudo isso aliado a uma vida saudável.

Podemos observar que a criatividade é percebida de forma semelhante pelos entrevistados. Para eles, criatividade está relacionado ao novo, seja na criação ou resolução de problemas. Eles mostram ciência de que nem todo trabalho é possível criativo sempre, e destacam a liberdade e o bem estar pessoal, como os fatores que incentivam a criatividade das pessoas, enquanto que de modo contrário, a negação constante, o volume e prazo de trabalho, além do tolhimento da liberdade, inibem a mesma criatividade.

No que se refere a ambiente criativo, o entrevistado revela que, para ele, é aquele onde as pessoas possam se sentir bem, como se pode ver em seu depoimento:

"Um ambiente criativo é um ambiente onde as pessoas possam se sentir livre para elas serem realmente quem elas são. E não finge ser pessoas que elas não são. [...] onde elas possam se sentir seguras para desenvolverem seus trabalhos. [...] [sobre os aspectos lúdicos do ambiente de trabalho] a partir do momento que você tá travado, não consegue pensar em um negócio legal, vai lá pra cima. Você abre a janela está olhando pro mar, você está cheio de palhetes com almofadas ao seu redor, você olha para uma parede toda

REAd | Porto Alegre - Edição 82 - N 3 - setembro/dezembro 2015 - p. 659-688 
Felipe Carvalhal \& Henrique Muzzio

desenhada por um artista, você olha pro lado tem um estúdio de design, você desce tem um freezer com cerveja.”

A entrevistada 02 disse que um ambiente criativo é aquele onde a pessoa se sente bem para trabalhar, e relata que esse ambiente precisa ter as melhores condições estruturais para isso. Além disso, retoma a questão do respeito e do tratamento por igual. Já a entrevistada 03, traz uma visão semelhando aos outros entrevistados. Ela afirma que um ambiente criativo é aquele que você se sente mais confortável, onde se deve buscar uma neutralidade entre as preferências da equipe. Argumenta que é importante ter um espaço para que a pessoa possa descansar e sair um pouco da pressão do trabalho.

Evidencia-se que um ambiente de trabalho criativo precisa estar atento a muito mais do que apenas os aspectos físicos, sendo estes considerados básicos. Os entrevistados destacaram um ambiente onde cada um se sinta bem, confortável, onde possam ser elas mesmas. Foi destacado também que um lugar para descansar e aspectos lúdicos podem ajudar na construção desse ambiente criativo.

Por fim, vale destacar a natureza dos negócios, bem como as variações de perfis do gestor pesquisado e das equipes lideradas, o que pode explicar as distinções apresentadas aqui.

\section{CONSIDERAÇÕES FINAIS}

Este trabalho possuiu como objetivo geral, analisar a liderança exercida por gestores da economia criativa, com vistas à liderança criativa. E buscou-se ainda, conhecer a atuação deles diante dos fatores da liderança criativa e os aspectos da criatividade; e verificar a relação da criatividade e produtividade a essa liderança.

Vistos os fatores que compõe a liderança criativa, o clima, ideias próprias, a resiliência e a ativação em rede, foram os que apresentaram uma visão mais coerente entre os entrevistados, e, inclusive, está mais alinhada ao que foi proposto para esse tipo de liderança. Observou-se que eles procuram criar um clima agradável em suas organizações. Os líderes procuraram fazer com que sua equipe esteja pronta para enfrentar problemas e se mostrem unidos para agirem quando surgir um obstáculo. No que tange às ideias próprias, há a preocupação em fazer com que sua equipe traga ideias novas, e incentiva isso de diversas maneiras, seja colocando essas pessoas em contato com outras, ou ainda, trazendo para perto

REAd | Porto Alegre - Edição 82 - N 3 - setembro/dezembro 2015 - p. 659-688 


\section{ECONOMIA CRIATIVA E LIDERANÇA CRIATIVA: UMA ASSOCIAÇÃO (IM) POSSÍVEL?}

delas novas experiências. E, em se tratando da ativação em rede, percebeu-se que os entrevistados incentivam o uso do networking por parte de sua equipe, para a resolução de problemas ou incremento de ideias.

Já em relação à plataforma de entendimento, visão compartilhada, e aprendizado vindo da experiência, foi percebido que estes apresentam certas divergências entre os respondentes. No caso da plataforma de entendimento, observou-se que há um esforço para fazer com que os liderados compartilhem dos mesmos valores e crenças. Quanto à visão compartilhada, um dos pontos mais frágeis, foi visto que nem todos os pesquisados deixam claro para sua equipe qual o sentido do que ela está fazendo, bem como quais os planos da organização. E referente ao aprendizado vindo da experiência, verifica-se que há que se melhorar um pouco, criando espaços de discussão construtiva do comportamento da equipe, por exemplo, fato apresentado em um dos casos. Os resultados desses fatores corroboram com os de Gallon e Ensslin (2008).

Em se tratando da produtividade, foi possível observar que todos os líderes consideram suas equipes produtivas, sendo os produtos/serviços resultantes de qualidade. Os entrevistados procuram acompanhar o andamento de seus membros, principalmente por meio de reuniões periódicas, ou em um caso específico diariamente, dado a participação que a entrevistada possui nas tarefas da empresa. Sobre a criatividade, observou visões semelhantes da mesma, e um fato de destaque é que o contato com outras pessoas, foi dito como aflorador dessa, enquanto que salientam para falta de liberdade e de bem-estar, como comprometedores da criatividade. Outro ponto a considerar, é que ambiente só é considerado criativo para os entrevistados, quando as pessoas se sentem bem nele, incluindo os aspectos físicos e os não tangíveis. Com isso, pode-se observar que há uma relação de simultaneidade entre a liderança criativa, uma melhor produtividade, apoio e incentivo à criatividade no ambiente de trabalho.

Respondendo ao objetivo geral proposto, pode-se afirmar que dentre os casos pesquisados, o entrevistado 01 apresenta os comportamentos que se espera de um líder criativo, enquanto que nos demais casos, é possível enxergar alguns aspectos que caracterizariam uma liderança criativa, mas em outros, ainda não. Os gestores da economia criativa ainda não exercem uma liderança criativa em sua plenitude, mas se esforçam para tal, é possível fazer uma associação entre ambas os fenômenos.

Instiga-se que pesquisas subsequentes investiguem as equipes de trabalhos desses gestores. Também sugere-se a ampliação da pesquisa para outros setores da economia. Essas

REAd | Porto Alegre - Edição 82 - N 3 - setembro/dezembro 2015 - p. 659-688 
Felipe Carvalhal \& Henrique Muzzio

inclinações são feitas para que se possa comparar com os resultados obtidos neste trabalho e poder consolidar um conhecimento nesse campo de estudo.

O ponto chave desta discussão foi enfatizar que estudar o fenômeno liderança requer mais que considerar o âmbito empresarial e sua evolução histórica, é necessário estar atento às perspectivas do indivíduo e da sociedade, e como eles se integram a esse tema, procurando compreender suas várias facetas e interseções, visto à busca de novos modelos teóricometodológicos.

\section{REFERÊNCIAS}

AMABILE, T. M. Motivating Creativity in Organizations: On Doing What You Love and Loving What You Do. California Management Review, v.40, n.01, p.39-58, 1997.

BARDIN, L. Análise de Conteúdo. Trad. Luís Antero Reto e Augusto Pinheiro. Lisboa: Edições 70 Ltda., 2008.

BRITISH COUNCIL. Mapping the creative industries: the UK context. London. 2005

BRYMAN, A. Liderança nas organizações. In: CLEGG, S.T, HARDY, C., NORD, W.R. (Orgs.). Handbook de Estudos Organizacionais - ação e análise organizacionais. São Paulo: Atlas, 2004, v.3, p. 256-281.

CARVALHAL, F. ESTILO DE LIDERENÇA DE JOVENS EMPREENDEDORES: UM ESTUDO DE AUTO PERCEPÇÃO DOS EMPREENDEDORES DA CIDADE DE ARACAJU - SERGIPE. 2012. 169f. Dissertação (Monografia em Administração de Empresas). Centro de Ciências Sociais e Aplicadas; Departamento de Administração. Universidade Federal de Sergipe, São Cristóvão, 2012.

CAVES, R.. Creative industries; contracts between art and commerce. Cambridge: Harvard University Press, 2000.

COHEN, R.; DENATALE, D.; MARKUSEN, A.; WASSALL, G. H. Defining the creative economy: industry and occupational approaches. Forth coming in Economic Development Quarterly, 2008.

REAd | Porto Alegre - Edição 82 - N 3 - setembro/dezembro 2015 - p. 659-688 
COSTA, A. D.; SANTOS, E. R. S. Economia criativa: novas oportunidades baseadas no capital intelectual. Economia \& Tecnologia. V. 25. Abril/Jun de 2011.

CRESWELL, J. W. Projeto de pesquisa: métodos qualitativos, quantitativos e mistos. $3^{\mathrm{a}}$ ed. Porto Alegre, Artmed: 2010.

DEHEINZELIN, L.. ECONOMIA CRIATIVA E EMPREENDEDORISMO CULTURAL. In: II ENECULT - Encontro de Estudos Multidisciplinares em Cultura. 2006. SalvadorBA. Faculdade de Comunicação/UFBA, maio de 2006.

DÓRIA, R. J, PEREIRA, H. J, SILVA, W. V. Liderança: Proposta de uma Escala de Medida Aplicada em uma Pesquisa no Setor Elétrico Brasileiro. IN: Encontro de Gestão de Pessoas e Relações de Trabalho, 1. 2007, Natal, RN. Anais... Natal, 2007.

FERREIRA, J. M, GIMENEZ, F. A. P, RAMOS, S. C. Potencial Empreendedor e Liderança Criativa: um Estudo com Varejistas de Materiais de Construção da Cidade de Curitiba/Pr. Revista de Administração da UNIMEP. V. 3, n. 3. P. 45-69. Set/Dez de 2005.

FIRJAN (FEDERAÇÃO DAS INDÚSTRIAS DO RIO DE JANEIRO). Indústria Criativa: Mapeamento da indústria criativa no Brasil. Rio de Janeiro.2012

FLICK, U. Introdução à pesquisa qualitativa. $3^{\mathrm{a}}$ ed. Porto Alegre: Artmed, 2009. FLORIDA, R. A ascensão da classe criativa. Porto Alegre. L\&PM, 2011.

GALLON, A. V.; ENSSLIN, S. R.. Potencial de liderança criativa em equipes de trabalho de empresas de base tecnológica incubadas. RAI - Revista de Administração e Inovação, São Paulo, v. 5, n. 1, p. 20-35, 2008.

GODOY, A. S. Pesquisa Qualitativa: Tipos Fundamentais. Revista de Administração de Empresas. São Paulo, Vol. 35, n 3, p.20-29, maio/jun 1995.

REAd | Porto Alegre - Edição 82 - Nº 3 - setembro/dezembro 2015 - p. 659-688 
Felipe Carvalhal \& Henrique Muzzio

GRINBERG, R.. Liderança Criativa. Disponível em: <http://migre.me/kZRmp >. Acesso em 10 de julho de 2014

HANASHIRO, D. M. M, NASSIF, F. J, NASSIF, V. M. J, CARVALHO, V. A. C, BIDO, D. S. Diversidade na Liderança: Há Diferença em Gênero? In: ENANPAD, 29, Brasília, DF, 2005. Anais... Brasília, 2005.

HOWKINS, J. The creative economy. How people make Money from ideas. London: Penguin Press, 2001.

HOWKINS, J.. The Mayor's Commission on the creative industries. In: HARTLEY, J. (Ed.). Creative Industries. Oxford: Black well Publishing, 2005. p. 117-125.

INACIO JUNIOR, E; F. A. P. GIMENEZ. Análise da validade e confiabilidade do team factory inventory- TFI: um instrumento para mensurar o potencial de liderança criativa em equipes empreendedoras. In: ENCONTRO NACIONAL DA ASSOCIAÇÃO NACIONAL DOS CURSOS DE POS-GRADUAÇÃO EM ADMINISTRAÇÃO, 28, 2004, Curitiba. Curitiba: EnAnpad, 2004.

MACHADO, R. M.. Da indústria cultural à economia criativa. ALCEU. V. 9, n.18. p. 83-95. Jan./jun. 2009

MERHI, D. Q; VASCONCELOS, K. C. A; FERNANDES, M. G. E; LOPES, V. M. G; SILVA, A. R. L. Cultura, Poder e Liderança nas Organizações: um estudo de caso no setor de celulose. In: Encontro da ANPAD, 32, 2008, Rio de Janeiro, RJ. Anais... Rio de Janeiro, 2008.

MIGUEZ, P. Economia criativa: uma discussão preliminar. 2007. p 95-114. In: Teorias e políticas da cultura: visões multidisciplinares. Organização NUSSBAUMER, G. M. EDUFBA, Salvador. 2007. 257p.

REAd | Porto Alegre - Edição 82 - Nº 3 - setembro/dezembro 2015 - p. 659-688 
MUZZIO, H.; PAIVA JÚNIOR, F. G.. A Gestão na Economia Criativa e a Identidade do Indivíduo Criativo Inovador: Em Busca de uma Convergência. In: Encontro da ANPAD, 38, 2014, Rio de Janeiro, RJ. Anais... Rio de Janeiro, 2014.

PRATT, A. C., HUTTON, T. A. Reconceptualising the relationship between the creative economy and the city: Learning from the financial crisis. Cities, v.33, p. 86-95, 2013.

RICKARDS, T.;MOGER, S.. Creative leadership processes in project team development: an alternative to Tuckman's stage model. British Journal of Management. V. 11, n. 4. p. 273283. December of 2000

SANTOS, H. B.; INÁCIO JÚNIOR, E. GIMENEZ, F. A. P.; TEIXEIRA, M. C..

Empreendedorismo e liderança criativa: um estudo com as pequenas empresas prestadoras de serviço de Maringá. In: EGEPE - ENCONTRO DE ESTUDOS SOBRE

EMPREENDEDORISMO E GESTÃO DE PEQUENAS EMPRESAS. 3., 2003, Brasília.

Anais... Brasília: UEM/UEL/UnB, 2003.

SERAFIM, M. C.; PINHEIRO, D.; JARA, E.; MELO, E. N.; AGUIAR, B.; BERNARDES, J. V.; RONCONI, L.; SILVA, A. Economia Criativa ou Indústria Criativa: Delimitação de um Conceito em Construção. In: Encontro de Economia Catarinense. 7. 2013. FlorianópolisSC. UFSC, maio de 2013.

STONER, J. A., FREEMAN, R. E. Administração. Rio de Janeiro: LTC, 1999.

TECCIO, E. L, NUNES, T. S, RISSI, M, CUNHA, C. J. C. A, NAKAYAMA, M. K. LIDERANÇA TRANSFORMACIONAL EM PROCESSOS DE TUTORIA: a identificação do estilo de liderança de Orientadores de Tutoria. CINTED-UFRGS. Novas Tecnologias na Educação. V. 8, n. 3, Dezembro, 2010

UNCTAD; Creative Economy Report 2008. Creative Economy: A Feasible Development Option. UN, 2008

UNCTAD; Creative Economy Report 2010.CreativeEconomy: A Feasible Development Option. UN, 2010

REAd | Porto Alegre - Edição 82 - N 3 - setembro/dezembro 2015 - p. 659-688 
Felipe Carvalhal \& Henrique Muzzio

YIN, R. K. Estudo de caso: planejamento e método. 2. ed. Porto Alegre: Bookman, 2001.

REAd | Porto Alegre - Edição 82 - N 3 - setembro/dezembro 2015 - p. 659-688 